\title{
Role of Serum Zinc Level and P300 Event Related Potential in Detection of Minimal Hepatic Encephalopathy
}

\author{
Ghada M. Galal1, Mahmoud Saif-Al-Islam1, Mohammed Abd Al-Ghafar Abd Al Rahman², \\ Nagwa S. Ahmed ${ }^{3}$, Mona M. Abd El Rhman'1 \\ ${ }^{1}$ Tropical Medicine Department, Sohag Medical Hospitals, Faculty of Medicine, Sohag University, Sohag, Eygpt \\ ${ }^{2}$ Audiology Department, Sohag Medical Hospitals, Faculty of Medicine, Sohag University, Sohag, Eygpt \\ ${ }^{3}$ Biochemistry Department, Sohag Medical Hospitals, Faculty of Medicine, Sohag University, Sohag, Eygpt \\ Email: mahmoud elislam@med.sohag.edu.eg
}

Received 12 April 2015; accepted 16 June 2015; published 19 June 2015

Copyright (C) 2015 by authors and Scientific Research Publishing Inc.

This work is licensed under the Creative Commons Attribution International License (CC BY).

http://creativecommons.org/licenses/by/4.0/

(c) (i) Open Access

\section{Abstract}

Background: Minimal hepatic encephalopathy (MHE) is defined as hepatic encephalopathy (HE) without symptoms on clinical/neurological examination, but with deficits in some cognitive areas that can only be measured by neuropsychometric testing. Aim: Our aim was to study serum zinc levels in cirrhotic patients with and without MHE and correlate it with the results of neuropsychological tests and P300 event related potential. Patients and Methods: Fifty-five patients with liver cirrhosis were recruited for the present study. All patients were subjected to full history taking, clinical examination, abdominal ultrasonography, laboratory investigations including liver function tests and serum zinc, psychometric studies (line tracing test and serial dotting test) and P300 event related potential. According to the results of psychometric studies and P300 event related potential, the patients were divided into 3 groups in addition to the control group. Results: Among the 55 patients included in the study, 30 patients had no clinical evidence of $\mathrm{HE}$ and 25 patients had overt HE with different grades. In patients with no clinical evidence of HE, psychometric tests and P300 event related potential revealed that 13 patients had MHE, while 17 had no HE. There were significantly lower serum zinc levels in patients with MHE and in cirrhotic patients without HE compared with the healthy controls. Also, zinc levels were significantly lower in higher grades of hepatic encephalopathy. Serum zinc levels showed positive correlation with serum albumin levels and inverse correlation with serial dotting test and P300 latency. Conclusion: Reduced serum zinc level and prolonged P300 latency can serve as predictors of minimal hepatic encephalopathy in cirrhotic patients. Zinc deficiency is common in cirrhotic patients with MHE. These findings may have important prognostic and therapeutic implications in MHE and overt HE patients with zinc deficiency. 


\section{Keywords}

\section{Liver Cirrhosis, Minimal Hepatic Encephalopathy, Serum Zinc, Psychometric Tests, P300 Latency}

\section{Introduction}

Hepatic encephalopathy is a potentially reversible, metabolically caused disturbance of central nervous system function that occurs in patients with acute or chronic liver disease. MHE is defined as HE without symptoms on clinical/neurological examination, but with deficits in some cognitive areas that can only be measured by neuropsychometric testing [1]. MHE has a high frequency among patients with liver cirrhosis (22\% - 74\%) and also occurs in patients with non cirrhotic liver disease such as portal vein thrombosis [2] or portosystemic shunt [3]. The true frequency of patients with MHE is unknown, firstly because the diagnostic criteria in use around the world are not entirely uniform, and secondly because MHE often remains undiagnosed due to the lack of evident symptoms [4]. However, numerous studies have shown that, although the neurological symptoms are slight, affected patients are markedly impaired in their quality of life and ability to work [5]. Various tools have been evaluated for the diagnosis of MHE including neuropsychological tests, neurophysiological tests as auditory brain stem response, p300 event, regional cerebral blood flow changes [6], magnetic resonance imaging and spectroscopy [7]. Several hypotheses attempt to explain the etiopathophysiology of HE. Metabolic products from the intestine are normally metabolized in the liver. However, in people with significant liver disease, impaired hepatic detoxification leads to systemic accumulation of by-products of gut metabolism, specifically ammonia [8]. Zinc is integrally involved in the metabolism of ammonia. Zinc deficiency markedly decreases the activity of the urea cycle enzyme, ornithine transcarbamylase, and zinc supplementation corrects this [9]. Similarly, zinc deficiency has been reported to impair activity of muscle glutamine synthetase, which causes hyperammonemia [10]. Glutamine synthetase activity has also been reported to be decreased in patients with hepatic encephalopathy [11].

\section{Aim of Work}

This work aimed to study serum zinc levels in cirrhotic patients with and without minimal hepatic encephalopathy and correlate it with the results of neuropsychological and auditory P300 event related potential.

\section{Patients and Methods}

This study is a case-control study. Fifty-five patients with liver cirrhosis were included. Patients with history of alcohol intake, drug abuse, drug intake as sedatives, diabetes mellitus, chronic renal failure, recent head trauma, trans-jugular intrahepatic porto-systemic shunt were excluded from the study in order to avoid coexistent neuropathy or other brain dysfunction. Patients with fever, sepsis or shock, were also excluded to avoid variations in nerve conduction caused by body temperature. Patients were divided into 3 groups:

Group I: Seventeen patients with liver cirrhosis without minimal hepatic encephalopathy.

Group II: Thirteen patients with liver cirrhosis with minimal hepatic encephalopathy. These patients were diagnosed based on the results of psychometric tests (serial dotting and line tracing test) and P300 event related potential. Patients who showed abnormal results of at least two of these tests were considered.

Group III: Twenty-five patients with liver cirrhosis with overt hepatic encephalopathy.

The control group: Included thirty healthy individuals (without any evidence of liver disease) matched for age and sex with the study group.

\subsection{Methods}

Before starting the study, the protocol was approved by faculty Ethics Committee. All participants signed written consents then the following were done: Full history taking, clinical examination, abdominal ultrasonography, laboratory investigations including liver function tests and serum zinc, psychometric studies and P300 event related potential.

Serum zinc level was determined by atomic absorption spectrophotometric technique using Perkin-Elmer 
atomic absorption spectrophotometer model 2380.

Psychometric studies:

A) Line tracing test (LTT):

It is a test of motor speed and accuracy. The subjects were asked to follow the route of the labyrinth without crossing or even touching the borderlines. For assessment of the test result the whole route was divided into small sections and each touching or crossing of the border in a section was counted. The number of mistakes and the time needed to go through the labyrinth, both, were the test results [11].

B) Serial dotting test (SDT):

It is a test of pure motor speed. The subjects were asked to put a dot in each of the 100 circles given on the sheet, after they had been prepared by dotting the 20 circles at the top of the sheet, first. Test result was the time needed to complete dotting of all circles [12].

$P 300$ event related potential:

We used odd-ball paradigm 1000 and $2000 \mathrm{~Hz}$ tone bursts within $50 \mathrm{~m} \cdot \mathrm{sec} \cdot$ rise/fall time and $200 \mathrm{~m} \cdot \mathrm{sec} \cdot$ plateau duration. It was presented at intensity level of $80 \mathrm{dBSPL}$. Stimuli were presented randomly at a rate of $0.5 / \mathrm{sec}$, $80 \%$ of them were $1000 \mathrm{~Hz}$ tone (target tones) with a total number of 100 stimuli in each run. The patient was instructed to raise his/her hand for each target stimulus.

Assessment of the severity of liver disease:

Child-Pugh score [13] was used to assess the severity of liver disease: Three laboratory tests (bilirubin, albumin, and prothrombin time), combined with the presence and severity of encephalopathy and ascites, were included in the Child-Pugh score.

\subsection{Statistical Analysis}

The data were analyzed by SPSS version 16 . Continuous data were expressed as mean \pm SD, and categorical data were expressed as numbers and percentages. Comparisons of differences between two groups were performed by the Student's t-test for the continuous data, Chi-square test or Fisher's exact test for categorical data. One-way ANOVA test for comparing the means of serum zinc levels in the studied groups. Pearson's $r$ correlation test was used to evaluate the correlation for continuous variables. P values of less than 0.05 were considered significant, $\mathrm{P}$ values of 0.05 - 0.01 were considered mild significant, $\mathrm{P}$ values of less than 0.01 - 0.001 were considered moderately significant and $\mathrm{P}$ values of less than 0.001 were considered highly significant.

\section{Results}

Among the 55 patients included in the study, 30 patients had no clinical evidence of HE and 25 patients had overt HE. Serum zinc level was variable in different grades of HE (Table 1). In patients with no clinical evidence

Table 1. Levels of serum zinc in the different categories of 55 cirrhotic patients and healthy controls.

\begin{tabular}{ccccc}
\hline & Number & Percent & \multicolumn{2}{c}{ Serum zinc } \\
\cline { 4 - 4 } & & & Mean \pm SD & Range \\
\hline 1) No clinical evidence of HE & 30 & & & $0.11-0.67$ \\
No HE & 17 & 56.67 & $0.36 \pm 0.20$ & $0.10-0.81$ \\
MHE & 13 & 43.33 & $0.25+0.19$ & $0.04-0.40$ \\
2) Overt HE & 25 & & & $0.04-0.3$ \\
Grade 1 & 8 & 32 & $0.17 \pm 0.14$ & $0.06-0.09$ \\
Grade 2 & 5 & 20 & $0.15 \pm 0.09$ & $0.08 \pm 0.02$ \\
Grade 3 & 6 & 24 & $0.07 \pm 0.03$ & $0.03-0.10$ \\
Grade 4 & 6 & 24 & $0.68 \pm 0.37$ & $0.20-1.40$ \\
\hline
\end{tabular}

HE: Hepatic encephalopathy; MHE: Minimal hepatic encephalopathy. 
of HE; psychometric tests (serial dotting test and line tracing test) and P300 event related potential revealed that 17 (56.67\%) patients had no HE, while 13 (43.33\%) patients had MHE. The etiology of liver cirrhosis in the studied patients was post chronic viral hepatitis C in 49 patients (90\%), post chronic viral hepatitis B in 3 patients (4.5\%), and of unknown etiology in 3 (4.5\%) patients.

Some laboratory characteristics and Child Pugh score of the 3 groups were shown in Table 2. Comparison of age, sex, neurological tests, and serum zinc between patients with no HE, MHE, and healthy controls were shown in Table 3.

The time needed for serial dotting test and line tracing test was significantly prolonged for cirrhotic patients with no HE and MHE than the healthy controls. Also, the time needed for serial dotting test and line tracing test was prolonged for patients with MHE than patients with no HE but with no statistically significant difference. The number of errors of line tracing test was more in patients with MHE than no HE and healthy controls but with no statistically significant difference. The mean P300 latency was significantly prolonged in patients with MHE than no HE and controls (Table 3).

Patients with no HE and MHE showed significant reduction in serum zinc levels compared to healthy controls $(\mathrm{P}=0.000)$. Also, there was more decrease in the serum zinc levels in patients with MHE than no HE, but the difference was statistically insignificant (Table 3).

Serum zinc level was significantly lower in higher grades of hepatic encephalopathy (Table 4, Figure 1).

There was a positive correlation between serum zinc levels and serum albumin levels. There was no correlation between serum zinc levels and either of serum bilirubin and prothrombin time. There was insignificant correlation between serum zinc levels and serial dotting test and line tracing test. There was a significant negative correlation between serum zinc levels and p300 latency (Table 5).

Table 2. Liver function tests and Child Pugh score of the studied groups.

\begin{tabular}{ccccccccc} 
& Healthy controls & No HE & MHE & Overt HE & & \multicolumn{3}{c}{ P value } \\
\cline { 7 - 9 } & $\mathbf{N}=\mathbf{3 0}$ & $\mathbf{N}=\mathbf{1 7}$ & $\mathbf{N}=\mathbf{1 3}$ & $\mathbf{N}=\mathbf{2 5}$ & $\begin{array}{c}\text { No HE versus } \\
\text { healthy controls }\end{array}$ & $\begin{array}{c}\text { Overt versus } \\
\text { No HE }\end{array}$ & $\begin{array}{c}\text { Overt versus } \\
\text { MHE }\end{array}$ \\
\hline Bilirubin (mg/dl) & $0.62 \pm 0.23$ & $1.36 \pm 0.59$ & $1.88 \pm 1.52$ & $5.87 \pm 9.10$ & $\mathbf{0 . 0 0 0}^{* * *}$ & $\mathbf{0 . 0 4 9}^{*}$ & 0.127 \\
Albumin (g/dl) & $4.03 \pm 0.93$ & $2.79 \pm 0.67$ & $2.39 \pm 0.70$ & $1.87 \pm 0.46$ & $\mathbf{0 . 0 0 0}^{* * *}$ & $\mathbf{0 . 0 0 0}^{* * *}$ & $\mathbf{0 . 0 0 8}^{* *}$ \\
Prothrombin time (sec) & $11.21 \pm 1.9$ & $15.33 \pm 1.90$ & $16.28 \pm 2.31$ & $20.44 \pm 6.07$ & $\mathbf{0 . 0 0 0}^{* * *}$ & $\mathbf{0 . 0 0 2}^{* *}$ & $\mathbf{0 . 0 2 3}^{*}$ \\
INR & $1.01 \pm 0.09$ & $1.35 \pm 0.16$ & $1.39 \pm 0.18$ & $1.71 \pm 0.51$ & $\mathbf{0 . 0 0 0}^{* * *}$ & $\mathbf{0 . 0 0 8}^{* *}$ & $\mathbf{0 . 0 4 1}^{*}$ \\
Child Pugh score & 5 & $6.76 \pm 1.56$ & $7.85 \pm 1.95$ & $12.04 \pm 2.17$ & $\mathbf{0 . 0 0 0}^{* * *}$ & $\mathbf{0 . 0 0 0}^{* * *}$ & $\mathbf{0 . 0 0 0}^{* * *}$
\end{tabular}

HE: Hepatic encephalopathy; INR: International normalized ratio; MHE: Minimal hepatic encephalopathy; *Mildly significant; N: Number; ${ }^{* * *}$ Moderately significant; Sec: second; ${ }^{* * * *}$ Highly significant.

Table 3. Comparison of age, sex, neurological tests, and serum zinc between patients with No HE, MHE, and healthy controls.

\begin{tabular}{|c|c|c|c|c|c|c|}
\hline & \multirow{2}{*}{$\begin{array}{l}\text { Cirrhotic patients } \\
\text { with No } \mathrm{HE} \\
\mathrm{N}=17\end{array}$} & \multirow{2}{*}{$\begin{array}{l}\text { Cirrhotic patients } \\
\text { with MHE } \\
\mathbf{N}=13\end{array}$} & \multirow{2}{*}{$\begin{array}{c}\text { Healthy } \\
\text { controls } \\
\mathbf{N}=30\end{array}$} & \multicolumn{3}{|c|}{ P value } \\
\hline & & & & $\begin{array}{l}\text { No HE versus } \\
\text { healthy controls }\end{array}$ & $\begin{array}{l}\text { MHE versus } \\
\text { healthy controls }\end{array}$ & $\begin{array}{c}\text { No HE versus } \\
\text { MHE }\end{array}$ \\
\hline Age (years) & $50.29 \pm 7.36$ & $49.23 \pm 4.01$ & $50.80 \pm 10$ & 0.844 & 0.467 & 0.617 \\
\hline Sex: male/female & $7 / 10$ & $8 / 5$ & $16 / 14$ & 0.423 & 0.619 & 0.269 \\
\hline Serial dotting test (sec) & $142.0 \pm 64.99$ & $164.46 \pm 56.42$ & $68.40 \pm 15.86$ & $0.000^{* * *}$ & $0.000^{* * *}$ & 0.330 \\
\hline Line tracing test (sec) & $196.24 \pm 105.16$ & $193 \pm 69.77$ & $95.17 \pm 31.56$ & $0.001^{* *}$ & $0.000^{* * *}$ & 0.920 \\
\hline Number of errors & $5.88 \pm 3.21$ & $11.23 \pm 11.70$ & $5.90 \pm 7.35$ & 0.991 & 0.148 & 0.133 \\
\hline P300 latency (m.sec) & $300.76 \pm 9.14$ & $338.23 \pm 16.81$ & $294.3 \pm 7.41$ & 0.483 & $0.000^{* * *}$ & $0.000^{* * *}$ \\
\hline Serum zinc (PPM) & $0.36 \pm 0.20$ & $0.25 \pm 0.19$ & $0.68 \pm 0.37$ & $0.000^{* * *}$ & $0.000^{* * *}$ & 0.136 \\
\hline
\end{tabular}

HE: Hepatic encephalopathy; Sec: Second; MHE: Minimal hepatic encephalopathy; m•sec: Millisecond; N: Number; PPM: part per million. 
Table 4. Serum zinc in early and late grades of HE.

\begin{tabular}{ccc}
\hline Serum zinc & Early grades of HE (grade 1 and grade 2) & Advanced grades of HE (grade $\mathbf{3}$ and grade 4) \\
\hline Mean \pm SD & $0.16 \pm 0.12$ & \\
Student's t-test & & P value $=\mathbf{0 . 0 2 1}$ \\
\hline
\end{tabular}

HE: Hepatic encephalopathy.

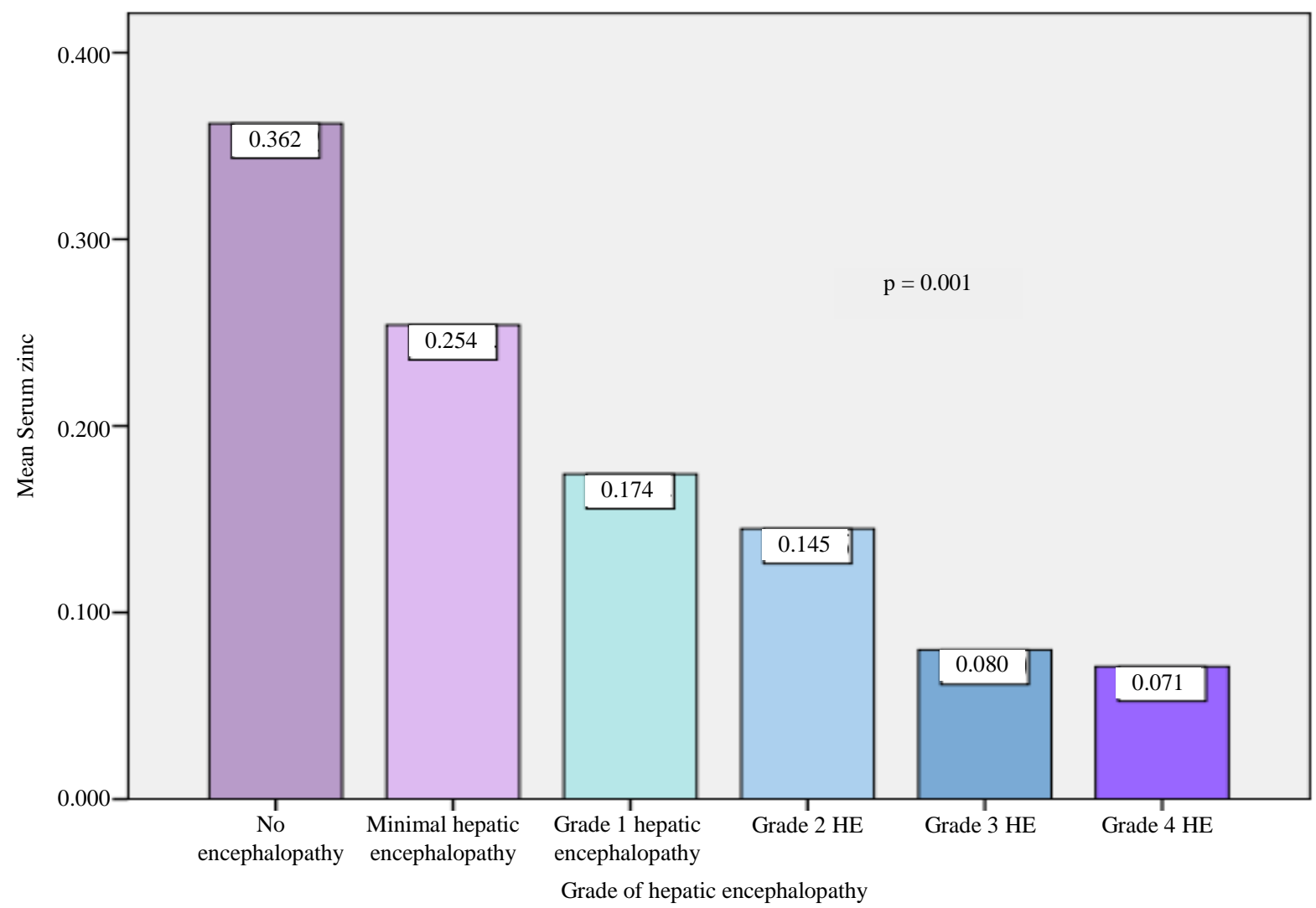

Figure 1. Serum zinc levels in the studied groups. Serum zinc levels were significantly lower in higher grades of hepatic encephalopathy $(\mathrm{F}=5.301, \mathrm{P}=0.001)$.

Table 5. Correlation between serum zinc and some laboratory data, psychometric tests (serial dotting and line tracing tests) and P300 event related potential.

\begin{tabular}{ccc}
\hline Variable & \multicolumn{2}{c}{ Serum zinc } \\
Bilirubin & $\mathrm{r}$ & P value \\
\cline { 2 - 3 } Albumin & -0.149 & 0.277 \\
Prothrombin time & 0.402 & $\mathbf{0 . 0 0 2}^{* *}$ \\
Serial dotting test & -0.182 & 0.184 \\
Line tracing test & -0.252 & 0.180 \\
errors & -0.174 & 0.358 \\
P300 latency & 0.182 & 0.334 \\
\end{tabular}

\footnotetext{
${ }^{* *}$ Moderately significant; ${ }^{`}$ Moderate negative correlation.
} 


\section{Discussion}

In our study we diagnosed MHE in 13 (43.33\%) patients out of 30 cirrhotic patients without overt encephalopathy by using combination of psychometric tests (line tracing test and circle dotting test) and auditory P300 event-related potential.

Psychometric testing is a well known method for diagnosing and measuring MHE. In our study we found a significant increase in the time needed for doing serial dotting test, line tracing test, and increase the number of errors in line tracing test in patients with No HE and patients with MHE than controls. This has been previously documented by Farid et al. (2000) [12] and Ramzy et al. (2008) [14]. When we compared the results of serial dotting test and line tracing test in patients with No HE and those with MHE insignificant differences were found. The mean value of P300 latency was significantly prolonged in No HE and MHE patients than healthy controls. Also, the P300 latency was significantly prolonged in MHE than No HE patients. This was in agreement with Farid et al. (2000) who found similar results [12]. This could be explained by P300 changes that may reflect early impairment of cognitive function. Thus, auditory P300 event-related potential is more sensitive than psychometric tests in detecting MHE.

Saxeno et al. (2002) found that the mean P300 latency in cirrhotic patients was significantly prolonged than in controls [15]. Weissenborn and his collogues (1990) found abnormally prolonged P300 latency in 30\% of cirrhotic patients without overt HE [16]. Also, Galli (1995) found that 54.5\% of cirrhotic patients with no clinical hepatic encephalopathy had significantly increased P300 latency. These changes of P300 latency indicate brain dysfunction even with no clinical evidence of hepatic encephalopathy the so called minimal hepatic encephalopathy [17]. On the other hand, other studies as Davies et al. (1990) found increase in the P300 latency only in patients with overt HE [18].

In the present study we found significantly lower serum zinc levels in both patients with MHE and cirrhotic patients without HE compared to the healthy controls. This is in agreement with McClain (1991) [19], Rahelić et al. (2006) [20] and Ramzy et al. (2008) [14]. This also has been previously documented by Yang et al. (2004) who concluded that cirrhotic patients suffering from subclinical portosystemic encephalopathy had lower serum zinc levels than control subjects [21]. The results confirmed Kugelmas' study (2000), who explained low zinc levels by malnutrition, insufficient protein intake, low absorption and high urinary excretion due to excessive diuretics administration [22]. Also, in decompansated cirrhotic patients, a greater proportion of zinc is albumin bound or $\alpha 2$ macroglobulin bound which may exaggerate the zinc deficiency state [23]. Therefore, zinc supplementation might play an important role in the prevention of HE by activating glutamine synthetase 1 [24].

In our study, serum zinc levels were variable with different grades of hepatic encephalopathy. It was significantly lower in higher grades of hepatic encephalopathy thus serum zinc deficiency may play a role in hepatic encephalopathy if not well corrected.

In the current study, there was a positive correlation between serum zinc levels and serum albumin levels. This is in agreement with loomba et al. (1995) [25] and Ramzy et al. (2008) [14].

We found that serum zinc levels had no correlatation with serum bilirubin and prothrombin time. However, other studies as Loomba et al. (1995) [25] and Ramzy et al. (2008) [14] showed that serum zinc levels were inversely correlated with prothrombin time. Also, Moriyama et al. (2006) showed positive correlation between serum zinc levels and serum bilirubin [26].

In our study, serum zinc levels showed insignificant negative correlation with serial dotting and line tracing tests. This may be related to other factors as educational levels of the patients. In addition, serum zinc levels showed significant negative correlation with P300 latency. This is in agreement with Ramzy et al. (2008) [14]. Zeng et al. (2003) found zinc administration can lead to improvement in psychometric test results [27].

The limitations to our study are the relatively small number of patients, and it would be interesting to determine whether this association holds true in longitudinal follow-up studies of larger groups of patients.

\section{Conclusion}

Reduced serum zinc level and prolonged P300 latency can serve as predictors of minimal hepatic encephalopathy in cirrhotic patients. Zinc deficiency is common in cirrhotic patients with MHE. Therefore, early correction of malnutrition and zinc supplementation may be important to minimize development of overt hepatic encephalopathy. These findings may have important prognostic and therapeutic implications in MHE and overt HE patients with zinc deficiency. 


\section{References}

[1] Ferenci, P., Lockwood, A., Mullen, K., Tarter, R., Weissenborn, K. and Blei, A.T. (2002) Hepatic EncephalopathyDefinition, Nomenclature, Diagnosis, and Quantification: Final Report of the Working Party at the $11^{\text {th }}$ World Congresses of Gastroenterology, Vienna, 1998. Hepatology, 35, 716-721. http://dx.doi.org/10.1053/jhep.2002.31250

[2] Dhiman, R.K., Saraswat, V.A., Sharma, B.K., Sarin, S.K., Chawla, Y.K. and Butterworth, R. (2010) Minimal Hepatic Encephalopathy: Consensus Statement of a Working Party of the Indian National Association for Study of the Liver. Journal of Gastroenterology and Hepatology, 25, 1029-1041. http://dx.doi.org/10.1111/j.1440-1746.2010.06318.x

[3] Sarin, S.K. and Nundy, S. (1985) Subclinical Encephalopathy after Portosystemic Shunts in Patients with Non-Cirrhotic Portal Fibrosis. Liver, 5, 142-146. http://dx.doi.org/10.1111/j.1600-0676.1985.tb00229.x

[4] Bajaj, J.S., Hafeezullah, M., Hoffmann, R.G. and Saeian, K. (2007) Minimal Hepatic Encephalopathy: A Vehicle for Accidents and Traffic Violations. American Journal of Gastroenterology, 102, 1903-1909. http://dx.doi.org/10.1111/j.1572-0241.2007.01424.x

[5] Schomerus, H. and Hamster, W. (2001) Quality of Life in Cirrhotics with Minimal Hepatic Encephalopathy. Metabolic Brain Disease, 16, 37-41. http://dx.doi.org/10.1023/A:1011610427843

[6] Bajaj, J.S., Hafeezullah, M., Hoffmann, R.G., Varma, R.R., Franco, J., Binion, D.G., Hammeke, T.A. and Saeian, K. (2008) Navigation Skill Impairment: Another Dimension of the Driving Difficulties in Minimal Hepatic Encephalopathy. Hepatology, 47, 596-604. http://dx.doi.org/10.1002/hep.22032

[7] Sunil, H.V., Mittal, B.R., Kumi, R., Chawla, Y.K. and Dhiman, R.K. (2012) Brain Perfusion Single Photon Emission Computed Tomography (SPECT) Abnormalities in Patients with Minimal Hepatic Encephalopathy. Journal of Clinical and Experimental Hepatology, 2, 116-121. http://dx.doi.org/10.1016/S0973-6883(12)60099-1

[8] Panickar, K.S., Jayakumar, A.R., Rao, K.V. and Norenberg, M.D. (2009) Ammonia-Induced Activation of p53 in Cultured Astrocytes: Role in Cell Swelling and Glutamate Uptake. Neurochemistry International, 55, 98-105. http://dx.doi.org/10.1016/j.neuint.2008.12.022

[9] Rabbani, P. and Prasad, A. (1978) Plasma Ammonia and Liver Ornithine Transcarbamoylase Activity in Zinc-Deficient Rats. American Journal of Physiology, 235, 203-206.

[10] Gorg, B., Qvartskhava, N. and Bidmon, H.J. (2010) Oxidative Stress Markers in the Brain of Patients with Cirrhosis and Hepatic Encephalopathy. Hepatology, 52, 256-265. http://dx.doi.org/10.1002/hep.23656

[11] Al Amin, H. and Saad, A. (2009) Subclinical Hepatic Encephalopathy: The Role of Neuropsychological and Electrophysiological Tools in Diagnosis. Current Psychiatry, 16, 215-222.

[12] Farid, M.N., El Sayed, N. and Essawy, H. (2000) Auditory P300 Event-Related Potential in Detection of Subclinical Hepatic Encephalopathy in Children. Current Psychiatry, 7, 199-213.

[13] Pugh, R., Murray-Lyon, I. and Dawson, J. (1973) Transection of the Oesophagus for Bleeding Oesophageal Varices. The British Journal of Surgery, 60, 646-649. http://dx.doi.org/10.1002/bjs.1800600817

[14] Ramzy, M., Dos, W., Mokhtar, S., Abdd Hafez, H., Abd El Kade, A., El Gohary, A., Obia, I. and Mahmoud, A. (2008) Serum Zinc Level as a Predictor of Suhclinical Hepatic Encephalopathy in Patients with Liver Cirrhosis. Arabian Journal Gastroentrology, 9, 101-105.

[15] Saxena, N., Bhatia, M., Joshi, Y.K., Garg, P.K., Dwivedi, S.N. and Tandon, R.K. (2002) Electrophysiological and Neuropsychological Tests for Diagnosis of Subclinical Hepatic Encephalopathy and Prediction of Overt Encephalopathy. Liver, 22, 190-197. http://dx.doi.org/10.1034/j.1600-0676.2002.01431.X

[16] Weissenborn, K., Scholz, M., Lautz, H.U., Schmidt, F.W. and Kunkel, H. (1990) Diagnostic and Prognostic Value of P300 Examination in Patients with Early Hepatic Encephalopathy. Journal of Hepatology, 10, S25.

[17] Gallai, V., Alberti, A., Balo, S., Mazzotta, G., Clerici, C., Gentili, G., Firenze, C. and Morelli, A. (1995) Cognitive EventRelated Potential in Hepatic Encephalopathy. Acta Neurologica Scandinavica, 91, 358-361. http://dx.doi.org/10.1111/j.1600-0404.1995.tb07021.x

[18] Davies, M.G., Rowan, M.J., MacMathina, P., Keeling, P.W.N., Weir, D.G. and Feely, J. (1990) The Auditory P300 Event Related Potential: An Objective Marker of the Encephalopathy of Chronic Liver Disease. Hepatology, 12, 688694. http://dx.doi.org/10.1002/hep.1840120412

[19] McClain, C.J., Marsano, L., Burk, R.F. and Bacon, B. (1991) Trace Metals in Liver Disease. Seminars in Liver Disease, 11, 321-339. http://dx.doi.org/10.1055/s-2008-1040450

[20] Rahelić, D., Kujundzić, M., Romić, Z., Brkić, K. and Petrovecki, M. (2006) Serum Concentration of Zinc, Copper, Manganese and Magnesium in Patients with Liver Cirrhosis. Collegium Antropologicum, 30, 523-528.

[21] Yang, S.S., Lai, Y.C., Chiang, T.R., Chen, D.F. and Chen, D.S. (2004) Role of Zinc in Subclinical Hepatic Encephalopathy: Comparison with Somatosensory-Evoked Potentials. Journal of Gastroenterology and Hepatology, 19, 375-379. http://dx.doi.org/10.1111/j.1440-1746.2003.03281.x 
[22] Kugelmas, M. (2000) Preliminary Observation: Oral Zinc Sulfate Replacement Is Effective in Treating Muscle Cramps in Cirrhotic Patients. Journal of the American College of Nutrition, 19, 13-15. http://dx.doi.org/10.1080/07315724.2000.10718908

[23] Frederickson, C.J., Suh, S.W., Silva, D., Frederickson, C.J. and Thompson, R.B. (2000) Importance of Zinc in the Central Nervous System: The Zinc-Containing Neuron. Journal of Nutrition, 130, 1471-1483.

[24] Chetri, K. and Choudhuri, G. (2003) Role of Trace Elements in Hepatic Encephalopathy: Zinc and Manganese. Indian Journal of Gastroenterology, 22, 28-30.

[25] Loomba, V., Pawar, G., Dhar, K.L. and Setia, M.S. (1995) Serum Zinc Levels in Hepatic Encephalopathy. Indian Journal of Gastroenterology, 14, 51-53.

[26] Moriyama, M., Matsumura, H., Fukushima, A., Ohkido, K., Arakawa, Y., Nirei, K., Yamagami, H., Kaneko, M., Tanaka, N. and Arakawa, Y. (2006) Clinical Significance of Evaluation of Serum Zinc Concentrations in C-Viral Chronic Liver Disease. Digestive Disease and Science, 51, 1967-1977. http://dx.doi.org/10.1007/s10620-005-9051-7

[27] Zeng, Z., Li, Y.Y. and Nio, Y.Q. (2003) An Epidemiological Survey of Subclinical Hepatic Encephalopathy. Chinese Journal of Hepatology, 1, 680-682. 